\title{
Validity of TUBEX Test versus Widal Test in Detection of Typhoid Fever in Zagazig, Egypt
}

\author{
Soha A Elhawari ${ }^{1}$, Mohamed H Mourad ${ }^{2}$ \\ ${ }^{1}$ Tropical Medicine Department, Faculty of Medicine, Zagazig University, Egypt \\ ${ }^{2}$ Clinical Pathology Department, Faculty of Medicine, Zagazig University, Egypt
}

Corresponding Author Soha A. Elhawari

Mobile:
01064218082
E mail:
saelhawary@.zu.edu.e
g

Key words: TUBEX, Widal test, Typhoid fever
Background and study aim: Typhoid fever is considered an endemic disease in Egypt. Widal test has been used for many years for diagnosing typhoid fever in the developing countries but it has serious doubts regarding its validity. TUBEX test is a simple rapid serodiagnostic test which has the advantages of Widal test without its controversy and it specifically detects the antibodies against $S$. typhi O9 lipopolysaccharide antigen. The aim of this study is to estimate the validity of TUBEX test, its sensitivity and specificity, as compared to Widal test.

Patients and methods: The study included 123 patients who presented with fever ( $\geq 3$ days duration and temperature $\geq 38^{\circ} \mathrm{C}$ ). Stool culture, Widal test, and TUBEX test were performed in all patients. TUBEX and Widal tests were compared as regard sensitivity and specificity in

\section{INTRODUCTION}

Typhoid fever is a multisystemic illness caused mainly by Salmonella enterica, subspecies enterica serovar typhi ( $S$. typhi) [1]. Ingestion of contaminated drinking water and food is the most common route of disease transmission $[2,3]$. Worldwide, typhoid fever continues to be a health problem in the developing countries whose sanitary conditions are poor. It is difficult to obtain sufficient data to estimate the burden of the disease in these areas, since many hospitals lack facilities for isolating the organism, and up to $90 \%$ of patients with typhoid are treated as outpatients. Community based studies have consistently shown higher levels of typhoid fever than public health figures suggest $[\mathbf{4 , 5}]$.

Blood, bone marrow and stool culture remains the most reliable methods for diagnosis of typhoid fever. Isolation is detection of typhoid fever using stool culture as a reference test.

Results: 40 out of 123 febrile patients had positive stool culture and considered to have typhoid fever. Among them, Widal test was positive in 34 patients, giving a sensitivity of $85 \%$, specificity of $88 \%$, positive predictive value of $77.3 \%$ and negative predictive value of $92.4 \%$ while TUBEX test was positive in 38 patients with sensitivity, specificity, positive predictive value and negative predictive value of $95 \%, 90.4 \%, 82.6 \%$ and $97.4 \%$ respectively. Both tests showed a high statistically significant agreement with stool culture.

Conclusion: TUBEX test shows higher sensitivity and specificity than Widal test. It is a simple test that gives rapid diagnosis for typhoid fever and can be useful in areas where facilities for culture are not available.

highest in the first week and becomes more difficult as time passes [6,7]. However, the methods of bacterial isolation are long and slow, and are not always successful as it requires laboratory equipments and technical training that are beyond the means of most primary health care facilities in the developing world. That is why; serologic analysis becomes more important [8,9]. In many countries, the Widal test is the most widely used test in typhoid fever diagnosis because it is relatively cheaper, easy to perform and requires minimal training and equipment [10]. The classic Widal agglutination test demonstrates the presence of antibodies in the serum of an infected patient against the $\mathrm{O}$ (somatic) and $\mathrm{H}$ (flagellar) antigens of S. typhi. A four-fold increase in the titer (from 1:40 to 1:160) in the course of the infection would be consistent with a typhoid infection. However, such a rise is not always demonstrable, even 
in culture-confirmed cases It is a simple test to perform, but it lacks sensitivity and specificity $[11,12]$.

Therefore, a fast, reliable, and affordable serodiagnostic test that is both sensitive and specific is required for rapid diagnosis and management of typhoid cases. TUBEX test is a simple and rapid in vitro diagnostic test for detection of acute typhoid fever. It specifically detects the presence of antibodies to the $S$. typhi O9 lipopolysaccharide antigen [13]. This antigen is highly specific to $S$. typhi and other Salmonella serogroup D bacteria by its extremely rare sugar ( $\alpha$-D-tyvelose). Elevated levels of anti-O9 IgM antibodies together with typical clinical symptoms of typhoid fever probably indicate acute infection with $S$. Typhi $[\mathbf{1 4 , 1 5 , 1 6 ]}$. The aim of this study was to estimate the validity of TUBEX test, a rapid serological test for detection of typhoid fever, its sensitivity and specificity as compared to Widal test.

\section{PATIENTS AND METHODS}

This comparative cross sectional study was carried out at Zagazig Fever Hospital, Sharkeia governorate, Egypt, within a period from April 2013 to April 2014. All admitted patients with fever ( $\geq 3$ days duration and temperature $\geq 38^{\circ} \mathrm{C}$ ) [17] were included in the study. Patients received antibiotic treatment for their symptoms or for any other reason, 2 weeks before admission to the hospital, were excluded from the study. This study was approved by the ethical committee of the Egyptian Ministry of Health, including the informed consents which were obtained from all patients.

Over a year, 123 febrile patients (91 males and 32 females), their ages ranged from 15 to 46 years old (30.1 \pm 9.4$)$ were included in this study. Febrile patients with positive stool culture (40 out of 123 patients) were considered to have typhoid fever, after complete history taking and thorough clinical examination. All patients were subjected to routine laboratory investigation including complete blood count, Liver and kidney profiles, complete urine and stool analysis and culture (during $1^{\text {st }}$ week of fever). Also, chest Xray, electrocardiogram and pelvi-abdominal ultrasound were done. TUBEX test was done and Widal test was performed twice, one week apart, to detect the rising titer.

\section{Stool culture:}

It was done for the detection of S. typhi in the stool specimen. One gram of each stool was inoculated into $10 \mathrm{ml}$ of selenite $\mathrm{F}$ broth and incubating at $37^{\circ} \mathrm{C}$ for $12-18$ hours. Selenite broth inhibits the motility of E. coli found in stools but does not kill this bacterium. A subculture of selenite broth on a selective agar which is (SalmonellaShigella). The plate is incubated at $37^{\circ} \mathrm{C}$ for 24 hours; the isolated colonies were identified as $S$. typhi by biochemical reaction and agglutination with specific antisera [18].

\section{TUBEX test (IDL Biotech, Sweden):}

A 5-minutes procedure for the detection of antiSalmonella $\mathrm{O} 9$ immunoglobulin $\mathrm{M}$ [IgM] in the patients serum by assessing their ability to inhibit the binding between 2 reagent particles: An indicator (colored) particle coated with a monoclonal antibody specific for the $\mathrm{O} 9$ antigen found in $S$. Typhi lipopolysaccharide (LPS) and a magnetic particle coated with S. Typhi LPS. Reaction of the indicator particle is revealed by magnetic separation of the particles and consequent color development [15].

\section{Statistical analysis:}

Data were checked, entered and analyzed using SPSS version 19 for data processing and statistic. Data were expressed as mean \pm SD for quantitative variable, number and percentage for qualitative one. Chi-squared $\left(\mathrm{X}^{2}\right)$ or student " $\mathrm{t}$ " test were used when appropriate. $\mathrm{P}<0.05$ was considered significant.

\section{RESULTS}

According to the inclusion criteria, 40 patients $(32.5 \%)$ were considered typhoid fever while 83 patients $(67.5 \%)$ were considered non-typhoid febrile patients. Both groups were matched as regard age and sex. Among the typhoid group, in addition to fever, the clinical presentation were headache in 22 patients $(55.0 \%)$, abdominal pain in 26 patients $(65.0 \%)$, diarrhea in 9 patients (22.5\%), constipation in 2 patients $(5 \%)$, relative bradycardia in 18 patients $(45.0 \%)$ and splenomegally in 11 patients $(27.5 \%)$. As regard laboratory parameters in this study, patients with typhoid fever showed significant reduction in WBCs $(1.9 \pm 5.5)$ and neutrophil counts $(44.9 \pm$ 11.2), while there was significant increase in lymphocytic count $(48.1 \pm 10.5)$. 
Results of positive cases of typhoid fever by different diagnostic tests among all the studied patients are shown in table (1). There was a highly statistical significant difference among both studied groups as regard rising titer of Widal test (O-antigen) $(\mathrm{P}<0.001)$ and TUBEX test $(\mathrm{P}<0.001)$ as shown in table $(2)$. Among all the 40 patients in the typhoid group, who were having positive stool culture, rising Widal test was positive in 34 patients, giving a sensitivity of $85 \%$, a specificity of $88 \%$, and a positive predictive value of $77.3 \%$ while TUBEX test was positive in 38 patients with sensitivity, specificity and positive predictive value of $95 \%, 90.4 \%$, and $82.6 \%$ respectively. Both tests showed a high statistically significant agreement with stool culture (Table 3 and 4).

Table (1): Positive cases of typhoid fever by different diagnostic tests among all studied patients.

\begin{tabular}{|c|c|c|}
\hline \multirow{2}{*}{ Diagnostic Test } & \multicolumn{2}{|c|}{ Total Number of Cases (123) } \\
\cline { 2 - 3 } Stool Culture & No & \% \\
$+\mathrm{ve}$ & 40 & $32.5 \%$ \\
$-\mathrm{ve}$ & 83 & $67.5 \%$ \\
\hline Rising titre of Widal test (O- antigen) & & \\
$+\mathrm{ve}$ & 44 & $33.9 \%$ \\
$-\mathrm{ve}$ & 79 & $66.1 \%$ \\
\hline TUBEX Test & & \\
$+\mathrm{ve}$ & 46 & $37.4 \%$ \\
$-\mathrm{ve}$ & 77 & $62.6 \%$ \\
\hline
\end{tabular}

Table (2): Results of the studied serological tests among both typhoid and non typhoid groups.

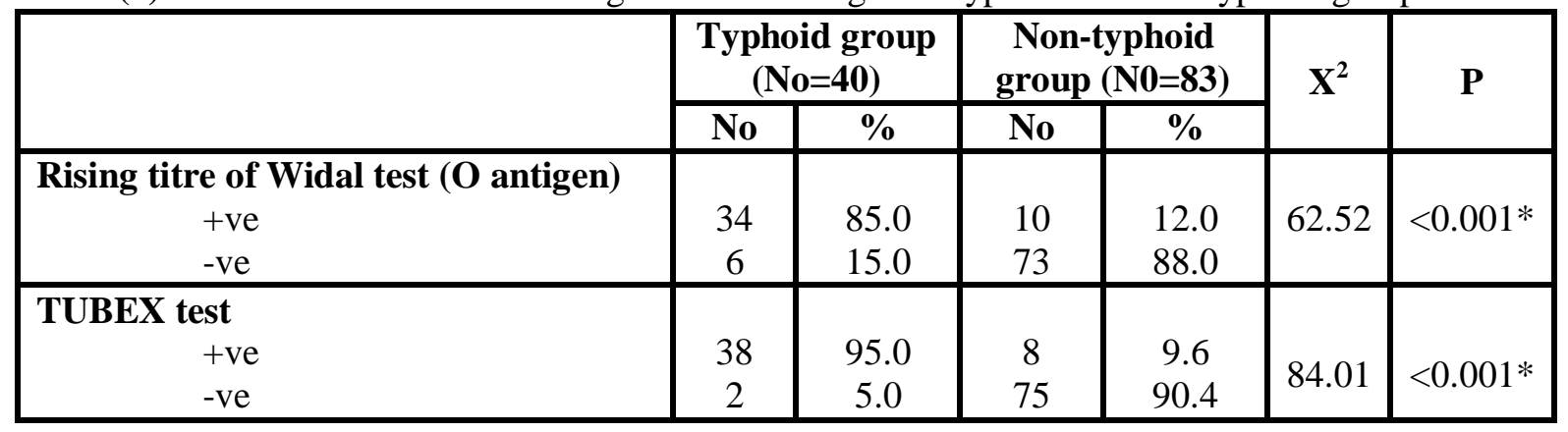

Table (3): Diagnostic validity of rising titre of Widal test (O-antigen) in relation to stool culture in diagnosis of typhoid fever

\begin{tabular}{|l|c|}
\hline Sensitivity & $85 \%$ \\
\hline Specificity & $88 \%$ \\
\hline Positive predictive value & $77.3 \%$ \\
\hline Negative predictive value & $92.4 \%$ \\
\hline Accuracy & $86.99 \%$ \\
\hline
\end{tabular}

Table (4): Diagnostic validity of TUBEX test in relation to stool culture in diagnosis of typhoid fever.

\begin{tabular}{|l|c|}
\hline Sensitivity & $95 \%$ \\
\hline Specificity & $90.4 \%$ \\
\hline Positive predictive value & $82.6 \%$ \\
\hline Negative predictive value & $97.4 \%$ \\
\hline Accuracy & $91.86 \%$ \\
\hline
\end{tabular}




\section{DISCUSSION}

The diagnosis of typhoid fever on clinical grounds is difficult, as the presenting symptoms are diverse [19]. Culture of the causative organism remains the most effective diagnostic procedure in suspected typhoid fever. However, its utility in early diagnosis is limited to early phase of illness thereby making the isolation of the organism difficult $[\mathbf{2 0 , 2 1}]$. Widal test has been used for many years for diagnosing typhoid fever in the developing countries but it has a low sensitivity, specificity and positive predictive value, which changes with the geographical areas making serious doubts regarding its validity. Sharing of $\mathrm{O}$ and $\mathrm{H}$ antigens by other Salmonella serotypes and other members of Enterobacteriaceae makes the role of Widal test even more controversial in diagnosing typhoid fever [5,22]. TUBEX test is a rapid, simple, and reliable sero-diagnostic test which studied in many endemic areas worldwide. In this study, the aim was to estimate the validity of TUBEX test versus the Widal test regarding sensitivity and specificity for detection of typhoid fever. It was observed that, TUBEX has a sensitivity of $95 \%$ and specificity of $90.4 \%$, which was higher than that of Widal test and comparable to the studies done elsewhere worldwide.

Figures of the present study showed that sensitivity, specificity, positive predictive value (PPV) and negative predictive value (NPV) of the TUBEX test were $95 \%, 90.4 \%, 82.6 \%$, and $97.4 \%$, respectively. These figures are lower than that obtained in a study by Lim et al. who found that TUBEX have a sensitivity of $100 \%$ and a specificity of $100 \%$ and was recommended its utility in the laboratory or by the bedside as a simple, rapid aid to the routine diagnosis of typhoid fever [13]. The $100 \%$ specificity of TUBEX is not surprising, since previous investigators found $S$. typhi LPS to be very specific [23,24]. The test uses polystyrene particle agglutination to detect IgM antibodies to the O9 LPS antigen. This antigen has been found highly specific, by its extremely rare sugar ( $\alpha$-D-tyvelose) $[8,13]$. IgM anti-O9 antibodies are normally not present in healthy individuals, thus TUBEX test is highly specific [25]. However, the O9 determinant is present not only in $S$. typhi but also in several other serotypes of Salmonella (serogroup D) such as $S$. enteritidis and $S$. sendai. However, many of these bacteria are not invasive and may not stimulate a systemic antibody response [13, 14]. In another study group of typhoid patients in
Pakistan, TUBEX test had to some extent a comparable sensitivity of $89.29 \%$, specificity of $84.62 \%$, PPV of $86.21 \%$ and NPV of $88 \%$ [26].

The effectiveness of TUBEX test for rapid diagnosis of typhoid fever patients was also studied in two different studies. First study was in India by Dutta et al. who evaluated the performance of TUBEX test in a community field site and compared it with Widal and Typhidot tests for diagnosis of typhoid fever. The sensitivity, specificity, PPV, and NPV of TUBEX were not better than that of Widal test. They stated that there is a need for more efficient rapid diagnostic test for typhoid fever especially during the acute stage of the disease. Until then, culture remains the method of choice [27]. The other study by Bakr et al. in Egypt also reported that TUBEX results are not superior to Widal test results. TUBEX test had sensitivity of $74.62 \%$, specificity of $75 \%$, PPV of $89.28 \%$ and NPV of $58.06 \%$ [28].

\section{CONCLUSION}

Both TUBEX and Widal tests showed comparability with stool culture. TUBEX test has higher sensitivity and specificity than Widal test. Since it is a simple test and takes less time in producing results, it can be used in all labs for rapid diagnosis of typhoid fever and it may be useful in areas where facilities for culture are not available.

Funding: None.

Conflicts of interest: None.

Ethical approval: Approved.

\section{REFERENCES}

1. Raffatellu M, Wilson P, Winter SE, Andreas J, Bäumler AJ. Clinical pathogenesis of typhoid fever. J Infect Dev Ctries 2008; 2: 260-266.

2. Luby SP, Faizan MK, Fisher-Hoch SP, Syed A, Mintz ED, Bhutta ZA. et al. Risk factors for typhoid fever in an endemic setting, Karachi, Pakistan. Epidemiol Infect 1998; 120: 129-138.

3. Gasem MH, Dolmans WM, Keuter MM, Djokomoeljanto RR. Poor food hygiene and housing as risk factors for typhoid fever in Semarang, Indonesia. Trop Med Int Health 2001; 6: 484-490.

4. Crump JA, Luby SP, Mintz ED. The global burden of typhoid fever. Bull World Health Organ 2004; 82(5): 346-53. 
5. Parry CM, Hien MB, Dougan MD, White NJ, Farrar MT. Typhoid fever. N Engl J Med 2002; 347: 1770-1782.

6. Wain J, Hosoglu S. The laboratory diagnosis of enteric fever. J Infect Dev Ctries 2008; 2(6): 421425 .

7. Wain J, Diep TS, Be Bay PV, Walsh AL, Vinh H, Duong NM. et al. Specimens and culture media for the laboratory diagnosis of typhoid fever. $J$ Infect Dev Ctries 2008; 2(6): 469-474.

8. Olsen SJ, Pruckler J, Bibb W, Nguyen TM, Tran MT, Nguyen TM. et al. Evaluation of rapid diagnostic tests for typhoid fever. $J$ Clin Microbiol. 2004; 42(5): 1885-1889.

9. Sattar AFM, Yusuf MA, Islam MB, Jahan WA. Different diagnostic procedure of typhoid fever: A review update. J Curr Adv Med Res. 2014; 1(2): 35-41.

10. Ley B, Mtove G, Thriemer K, Thriemer K, Amos B, Seidlein LV. et al. Evaluation of the Widal tube agglutination test for the diagnosis of typhoid fever among children admitted to a rural hospital in Tanzania and a comparison with previous studies. BMC Infect Dis 2010; 10: 180.

11. Olopoenia LA, King AL. Widal agglutination test-100 years later: still plagued by controversy. Postgrad Med J 2000; 76: 80-84.

12. House D, Chinh NT, Diep TS, Parry CM, Wain J, Dougan G. et al. Use of paired serum samples for serodiagnosis of typhoid fever. J Clin Microbiol 2005; 43: 4889-90.

13. Lim PL, Tam FC, Cheong YM, Jegathesan M. One-step 2-minute test to detect typhoid-specific antibodies based on particle separation in tubes. $J$ Clin Microbiol. 1998; 36(8): 2271-2278.

14. Jann K, Westphal O. Microbial polysaccharides. In: Sela M. (ed). The antigens. Vol. 3. New York: Academic Press. 1975; p: 1-25.

15. Tam FC, Lim PL. The TUBEX typhoid test based on particle-inhibition immunoassay detects $\operatorname{IgM}$ but not IgG anti-O9 antibodies. $J$ Immunol Methods 2003; 282: 83-91.

16. Feleszko W, Maksymiuk J, Oracz G, Golicka D, Szajewska H. The TUBEX typhoid test detects current Salmonella infections. J Immunol Methods. 2004; 285(1): 137-138.

17. W.H.O. Surveillance of Communicable Diseases: A Training Manual. Geneva: Regional Office for the Eastern Mediterranean, 1998. WHO-EMm/ CDS/52/E/L.
18. Forbes B, Sahm DF, Weissfeld AS. Bailey \& Scott's Diagnostic Microbiology, 11th ed; Chapter 62; Mosby Elsevier, St. Louis, MO; 2002: 954-71.

19. Stuart BM, Pullen RL. Typhoid fever: Clinical analysis of three hundred and sixty cases. Arch. Intern. Med. 1946;78: 629-661.

20. Farooqui BJ, Khurshid M, Ashfaq MK, Khan MA. Comparative yield of Salmonella Typhi from blood and bone marrow cultures in patients with fever of unknown origin. J. Clin. Pathol. 1991; 44: 258-259.

21. Vallenas C, Hernandez H, Kay B, Black R, Gotuzzo E. Efficacy of bone marrow, blood, stools and duodenal content cultures for bacteriologic confirmation of typhoid fever in children. Pediatr Infect Dis 1985; 4: 496-498.

22. Sherwal BL, Dhamija RK, Randhawa VS, Jais M, Kaintura A, Kumar M. A Comparative srudy of Typhidot with Widal test in patients of Typhoid fever .JIACM 2004; 5(3): 244-246.

23. Shaheen HI, Girgis NI, Rodier GR, Kamal KA. Evaluation of the response of human humoral antibodies to Salmonella typhi lipopolysaccharide in an area of endemic typhoid fever. Clin Infect Dis. 1995 ; 21(4): 1012-1013.

24. Sippel J, Bukhtiari N, Awan MB, Krieg R, Duncan JF, Karamat KA. et al. Indirect immunoglobulin $\mathrm{G}(\mathrm{IgG})$ and IgM enzyme-linked immunosorbent assays (ELISAs) and $\operatorname{IgM}$ capture ELISA for detection of antibodies to lipopolysaccharide in adult typhoid fever patients in Pakistan. J. Clin. Microbiol. 1989; 27:1298-1302.

25. Kawano RL, Leano SA, Agdamag DM. Comparison of serological test kits for diagnosis of typhoid fever in the Philippines. $J$ Clin Microbiol. 2007; 45: 246-247.

26. Jaffery G, Anwar MS, Hussain W, Maqbool S. Serological diagnosis of typhoid fever in children: a comparative evaluation of Salmonella Typhi O-9 antigen based rapid assay. Pak Pediatr J. 2005; 29: 27-33.

27. Dutta S, Sur D, Manna B, Sen B, Deb AK, Deen JL. Evaluation of new generation serologic tests for the diagnosis of typhoid fever: data from a community-based surveillance in Calcutta, India. Diag Microbiol Infect Dis. 2006; 56(4): 359-365.

28. Bakr WM, El Attar LA, Ashour MS, El Tokhy AM. Tubex test versus Widal test in the diagnosis of typhoid fever in Kafr El-Shekh, Egypt. J Egypt Public Health Assoc. 2010; 85(5-6): 285-296. 
Peer reviewer: Mostafa Elshamy, Professor of Tropical Medicine and Hepatogastroenterology, Faculty of Medicine, Zagazig University, Egypt.
Editor: Tarik Zaher, Professor of Tropical Medicine and Hepatogastroenterology, Faculty of Medicine, Zagazig University, Egypt. 